\title{
A Colônia do Sacramento na historiografia nacional e os usos da Historia Topografica e Belica de Simão Pereira de Sá
}

\author{
Tamyres Gonçalves Palma Zimmer ${ }^{1}$
}

Resumo: A Colônia do Sacramento - hoje território uruguaio - teve papel extremamente relevante na colonização do extremo-sul da América portuguesa a partir do século XVII. Apesar de ter sido o primeiro povoado português tão ao sul do território, por muitas décadas a existência e importância da Colônia foi descartada por historiadores nacionalistas que buscavam esquecer este território perdido. Para compreender esta representação, selecionei, a partir de critérios por mim explanados ao início do artigo, trabalhos de diversas tipologias para analisar a maneira como a Colônia do Sacramento é tratada ou não - na historiografia nacional. Por fim, analiso obras que fizeram uso da crônica de Simão Pereira de Sá como detentora da verdade, de maneira acrítica, confiando nas palavras daquele erudito sem se perguntar quais seriam os interesses por trás de sua retórica.

Palavras-chave: Colônia do Sacramento, História do Brasil Colônia, Historiografia

Abstract: The Sacrament Colony - which now belongs to Uruguay - was extremely important in the colonization of the Portuguese America's far South during the 17th century. Even though it was the first place in the far South populated by the Portuguese, the existence of the Colony was long ignored by nationalist historians who sought to forget this lost territory. To comprehend this representation, I've selected, based on the criteria explained by myself at the start of the article, works of different typologies to analyze the way which the Colony is treated in the national historiography. To conclude, I analyze works that used the chronicles of Simão Pereira de Sá as the owner of the truth, in a non-critical way, giving credit to the erudite's words without asking what his interests behind his rhetorical were.

Key Words: Sacrament Colony, Brazilian Colonial History, Historiography

${ }^{1}$ Graduada em História pela Universidade Federal do Paraná - 2013. 
O presente trabalho pretende analisar as representações da Colônia do Sacramento na historiografia brasileira e os usos teóricos feitos da obra Historia Topografica e Belica da Nova Colonia do Sacramento $^{2}$ de Simão Pereira de Sá.

Para a análise da discussão historiográfica feita em torno da Colônia do Sacramento fiz uso de diferentes categorias de produções historiográficas, como obras da historiografia tradicional, trabalhos acadêmicos e paradidáticos, além de livros didáticos. Busquei trabalhar com uma historiografia mais recente, e para ter um trabalho mais amplo e completo, localizei muitos dos trabalhos antigos citados nesta historiografia mais atual, para traçar um paralelo entre eles. A seleção dos livros didáticos se deu através de um procedimento simples: selecionei todos os livros de ensino fundamental e médio disponíveis em uma biblioteca de um colégio particular de Curitiba.

Um dos autores selecionados para analisar neste trabalho é Walter Spalding. Nascido em 1901, em Arroio dos Ratos, Spalding foi historiador e chegou a ser membro do Instituto Histórico e Geográfico Brasileiro e do Instituto Histórico e Geográfico do Rio Grande do Sul, sendo um autor de linha mais tradicional na escrita da história. Uma de suas obras foi selecionada para se trabalhar no presente artigo, sendo ela a Gênese do Brasil-Sul (1953).

2 SÁ, Simão Pereira de. Historia Topografica e Belica da Nova Colonia do Sacramento do Rio da Prata, Escrita por Ordem do Governador e Capitão Geral do Rio de Janeiro em 1737 e 1777. Porto Alegre: Arcano 17, 1993. 
Na obra Gênese do Brasil-Sul, Spalding argumenta que a expansão portuguesa para a fronteira sul se deu efetivamente após 1737 - portanto, o autor ignora as duas primeiras colonizações portuguesas da Colônia do Sacramento, de sua fundação em 1680 a 1705, e de 1715 a 1737, a partir da fundação da vila de Rio Grande de São Pedro. Ele aponta a fundação de Sacramento em $1^{\circ}$ de janeiro de 1680 , mas para o autor, até 1737 viveu-se um período de dominação castelhana no território do Rio Grande do Sul, e Sacramento teve pequena importância nesta expansão, sendo a vila de Rio Grande de São Pedro mais decisiva na colonização do sul da colônia. Sacramento serviu, para ele, como meio de fazer o desconhecido Rio Grande ${ }^{3}$ começar "a ser desbravado e conquistado para a Coroa portuguesa" ${ }^{4}$.

Segundo Spalding, Sacramento tinha pouca força para efetivamente atrair o povoamento do continente de Rio Grande. Para o autor, esta colonização se deu efetivamente através do descobrimento do gado bovino e equino da região,

podendo-se, mesmo, afirmar que foi graças a êsse gado que Portugal ficou de posse da capitania, pois a questão da Colônia, embora surgida mais ou menos simultaneamente à busca do gado, pouco teria influido, no seu povoamento central, não fôsse êsse elemento ambicionado, verdadeiro ouro ambulante que encheu de cobiça tôdas as classes sociais de então, formando um tipo à parte, sui generis, - o gaúcho-soldado-povoador, - legítimo fronteiro,

\footnotetext{
${ }^{3}$ SPALDING, Walter. Gênese do Brasil-Sul. Porto Alegre: Livraria Sulina Editora, 1953. p. 20.

${ }^{4}$ Idem, p. 20.
} 
autêntico herói na luta contra invasores e na manutenção dos lindes brasileiros do extremo meridional. [SPALDING, 1953, p. 30]

Embora a Colônia do Sacramento não tenha alcançado a posição de uma importante vila de colonização por sua situação fronteiriça e de constantes invasões castelhanas, ela atraiu a colonização para o extremo sul da colônia portuguesa, tanto pela sua localização e importância como posto comercial, quanto de fato pela grande quantidade de gado vacum e pelos ótimos pastos dos pampas. Negar isto é tendencioso, como vemos Walter Spalding ser. O autor foi membro do IHGB e do IHGRS, e como membro destes Institutos, é defensor de uma história com uma visão mais tradicionalista, defensora das origens portuguesas de nosso país, dedicada a exaltar as qualidades portuguesas e a ignorar qualquer influência "estrangeira" na nossa formação.

A negação da importância da Colônia do Sacramento enquadra-se na exaltação portuguesa em detrimento do outro, pois embora tenha tido grande importância para a Colônia Portuguesa no século XVIII, Sacramento é um território perdido aos castelhanos, portanto, menos digna de lembranças e honras. Para o autor, a construção do estado do Rio Grande do Sul se deu através dos esforços "daqueles outrora pacíficos e serenos tropeiros lagunenses e paulistas, aliados, a partir de 1752, aos não menos pacíficos, bondosos e serenos 
açorianos que as ilhas nos mandaram como dádiva dos céus."

A obra onde consta a emblemática frase sobre a Colônia do Sacramento "ninho, antes de contrabandistas que de soldados" de Capistrano de Abreu também foi selecionada para figurar neste artigo. Capistrano de Abreu nasceu em 1853, e com 22 anos seguiu para a corte no Rio de Janeiro em busca de um lugar entre os homens letrados que ali se encontravam. Sua escrita da história teve grande influência da obra de Francisco Adolfo de Varnhagen - importante membro do IHGB, e também prezava por uma história nacionalista e tradicionalista.

Em Capítulos da História Colonial - de 1500 a 1800, Abreu trata a Colônia do Sacramento de maneira pejorativa e desdenhosa. A valorização da constituição de uma identidade nacional, de um estadonação ao final do século XIX e início do século XX levaram à supervalorização do processo de expansão e conquista territorial, sendo Sacramento um território perdido, portanto motivo de vergonha e alvo de desmerecimento e esquecimento quando possível.

No capítulo onde Capistrano de Abreu cita a Colônia do Sacramento, há um claro desmerecimento da mesma, mas mais do que isto, a narrativa gira praticamente em torno de avanços diplomáticos e conquistas territoriais, onde Sacramento aparece apenas nos momentos em que sua presença é inevitável para a veracidade dos fatos narrados.

Além de não valorizar o território perdido aos castelhanos, Abreu desdenha dos homens que viveram em Sacramento, pois se a

${ }^{5}$ SPALDING, Walter. Gênese do Brasil-Sul. Porto Alegre: Livraria Sulina Editora, 1953. p. 31. 
mesma era para ele "um ninho de contrabandistas", não há como imaginar que ele tenha valorizado os portugueses que tentaram povoar Sacramento. Para o autor, em Sacramento - inclusive - se deu origem a um terrível tipo que povoou os pampas riograndenses: o gaúcho. Diferentemente de Walter Spalding, em que vemos o gaúcho descrito como o homem bravo, o corajoso, que através de sua espada e montaria conquistou e preservou o continente do Rio Grande, em Capistrano de Abreu o gaúcho é descrito como uma criatura vil, "originários da margem esquerda do Prata [...] e ainda não assimilados de todo à civilização" . Sua repulsa e recusa a tudo aquilo que não mais faz parte do todo nacional o leva a evitar o que pode ter tido influências não portuguesas e se possível, esquecer totalmente.

Um livro atual de historiografia selecionado para analisar aqui é da historiadora Ieda Gutfreind. A autora é mestra em História pela Pontifícia Universidade Católica do Rio Grande do Sul e doutora em História Social pela Universidade de São Paulo.

Em seu livro A Historiografia Rio-grandense, vemos que Gutfreind se propõe a fazer um levantamento da produção sobre a história gaúcha, pois ela via a necessidade de um trabalho mais completo sobre o assunto. Porém, já na introdução do livro percebemos as escolhas da autora em sua seleção de trabalhos a serem analisados, e vemos que a colonização portuguesa da região do Rio da Prata não é considerada o pontapé do surgimento do Rio Grande do Sul. Os autores

${ }^{6}$ ABREU, Capistrano. Capítulos da História Colonial - 1500 - 1800. Brasília: Conselho Editorial do Senado Federal, 1998, p. 186. 
selecionados por Gutfreind são - em sua maioria - defensores da história lusa do Rio Grande e, portanto, ignoram as interações com os castelhanos no extremo sul meridional da colônia portuguesa, que foi o efetivo ponto de interesse que levou os portugueses a colonizar o continente do Rio Grande.

A autora apresenta brevemente o dualismo que separa a historiografia riograndense por ela analisada em seu livro. De um lado estão a maioria dos autores, que defendem a matriz lusa na concepção do estado gaúcho. O primeiro defensor da matriz lusa em negação às influências platinas na gênese do Rio Grande do Sul foi o historiador Aurélio Porto, na década de 20 do século passado. Segundo a autora, "Souza Docca dá continuidade e desloca o discurso, tornando-o mais convincente, Othelo Rosa expande e aprofunda a matriz lusitana, cabendo a Moysés Vellinho seu aprimoramento linguístico e literário, finalizando sua trajetória" ${ }^{\text {" }}$, sendo portanto este o trajeto que o discurso criado por Porto toma nas mãos de outros historiadores. Do outro lado estão alguns poucos autores que defendem as influências castelhanas na formação do estado e de seu povo - a matriz platina -, levando em consideração o período de convívio às margens do Rio da Prata e as Missões Jesuíticas fundadas por jesuítas espanhóis no século XVII.

Embora apresente alguns autores que defendam a matriz platina do estado do Rio Grande do Sul, nota-se que a autora também tende à matriz lusa, pois num livro sobre historiografia riograndense

7 GUTFREIND, Ieda. A Historiografia Rio-Grandense. 2a ed. - Porto Alegre: Ed. Universidade/UFRGS, 1998, p. 45. 
não há um único capítulo que trate a Colônia do Sacramento e sua importância na empresa lusa de colonização do extremo sul meridional. Embora tenha sido uma região de efervescente contato com os castelhanos e tenha se tornado território espanhol depois de um século de disputas bélicas e diplomáticas, Sacramento foi fundada pelos portugueses na sua campanha de expansão territorial no final do século XVII.

Outro autor que fora membro do IHGRGS selecionado para ter uma obra analisada por mim neste artigo foi Moysés Vellinho e seu livro Fronteira. Vellinho nasceu em 1902, em Santa Maria, e faleceu em 1980, em Porto Alegre. Em sua obra vemos a defesa da matriz ideológica lusa na formação do Rio Grande do Sul. Carina Santos de Almeida ${ }^{8}$ caracteriza esta busca pela matriz lusa na formação do estado gaúcho como uma forma de encontrar uma unidade regional com o todo do Brasil e portanto "consolidar a unidade nacional", sentimento importante num contexto de consolidação de um Estado Nacional e sua identidade.

Embora trate da consolidação das fronteiras gaúchas, Vellinho mal trata do início da colonização do extremo sul da colônia a partir da fundação de Sacramento. Laguna é muito mais importante neste processo expansionista para Vellinho do que Sacramento. O autor aponta inclusive mais o grande espaço territorial vazio entre Laguna e

${ }^{8}$ ALMEIDA, Carina Santos de. O debate historiográfico entre Moysés Vellinho e Manoelito de Ornellas. Spartacus - Revista Eletrônica dos Discentes de História, 2007.

${ }^{9}$ Idem, p. 2. 
Sacramento do que a importância dessa praça. Os pedidos de povoamento deste espaço territorial aparecem mais enfatizados do que a importância estratégica de Sacramento, embora o autor aponte brevemente que "apesar de perdido na distância, a função estratégica do escravo lusitano se mantinha a mesma, por certo"10.

Embora cite Sacramento, pois seria impossível tratar da formação das fronteiras gaúchas sem citá-la, Vellinho o faz superficialmente, preferindo dar enfoque nas colonizações que deram certo, bem como na atitude dos nobres portugueses que lutaram para estabelecer estas fronteiras e impedir o avanço castelhano. Um bom exemplo disso é a narrativa sobre o cerco castelhano de 1735-37. Vellinho aponta a tentativa de socorro à praça com o envio de José da Silva Paes à mesma, com reforços e mantimentos, tendo o plano todo sido arquitetado primeiro no Rio de Janeiro e consolidado em Laguna, mas o plano falhara. A tentativa de se livrar do cerco espanhol não deu certo, e para não reconhecer uma derrota militar lusa, as intempéries do tempo foram responsabilizadas, a fim de preservar o nome e a honra dos homens portugueses.

Sua valorização do luso em detrimento do castelhano reafirma sua matriz lusa na formação do Rio Grande do Sul, pois seria inadmissível que os portugueses perdessem Sacramento em batalha aos castelhanos. Mais digno é colocar a natureza e suas peças lançadas contra os portugueses como culpadas de seu fracasso na tentativa de

${ }^{10}$ VELLINHO, Moysés. Fronteira. Porto Alegre: Editora Globo, 1975, p. 15. 
findar o cerco a Sacramento.

Do historiador e militar Riograndino da Costa e Silva selecionei o livro Notas à margem da História do Rio Grande do Sul (1968). As informações que obtive do autor foram encontradas na orelha do livro. $\mathrm{O}$ autor dedicou grande parte de suas pesquisas à história do Rio Grande do Sul e foi membro efetivo do IHGRGS.

Neste livro, vemos que Costa e Silva perpassa a Colônia do Sacramento apenas quando é inevitável falar da mesma. Um dos subcapítulos de seu livro tem por título "A primeira povoação fundada à margem do Canal", onde o autor tratará sobre as povoações portuguesas no continente, o que nos dá margem para supormos que trataria da fundação da Colônia do Sacramento em 1680, mas esse prefere considerar como primeira povoação a fundação de um pequeno núcleo populacional pelos lagunistas, em 1725, tendo em João de Magalhães o homem à frente desta incursão.

O autor ignora os 45 anos prévios da existência da Colônia do Sacramento, provavelmente por ela atualmente ser território uruguaio, mas até 1777 Sacramento era território português, mesmo sendo constantemente disputada com Castela. É compreensível que Sacramento não figure como a primeira povoação do Rio Grande do Sul, pois hoje Sacramento é território uruguaio. Entretanto, ignorar o ímpeto português de colonizar o território oriental do Prata para impedir o avanço castelhano por estas terras, e ter acesso ao lucrativo comércio vigente no Rio da Prata, e os esforços - mesmo que pequenos - de tornar 
Sacramento mais ligada ao restante da Colônia, com a fundação do forte Jesus, Maria e José em 1737, que viria a ser Rio Grande de São Pedro, é algo muito arbitrário da parte do autor.

No trabalho do professor Fábio Kühn intitulado Breve História do Rio Grande do Sul vemos um posicionamento diferente em contraponto ao posicionamento historiográfico de Ieda Gutfreind e dos autores tradicionalistas em relação à importância da interação lusa com os castelhanos no extremo sul do continente. $\mathrm{O}$ autor critica duramente os trabalhos que supervalorizam "as rivalidades e a exclusão entre povoadores hispânicos e lusitanos"11 em favor do mito da construção totalmente lusa do Rio Grande do Sul, sem as influências hispânicas que foram grandes, não há como negar. O autor critica Moysés Vellinho e sua obra Fronteira, alegando que a construção que se faz nesta obra é uma tentativa de demonstrar na gênese do estado gaúcho a presença apenas de ilustres homens portugueses, que trabalharam e lutaram para que aquele pedaço de chão fosse português, e consequentemente brasileiro. Esta construção de Vellinho exclui a história de locais que tiveram o predomínio castelhano em sua origem, como os Sete Povos das Missões. Para Fábio Kühn, esta negação da influência castelhana faz parte da visão da história tradicional, que via que

o Rio Grande estaria historicamente determinado a ser brasileiro, o que fazia com que tudo que pudesse lembrar as inegáveis influências platinas

${ }^{11}$ KÜHN, Fábio. Breve História do Rio Grande do Sul. $2^{\mathrm{a}}$ edição. Porto Alegre: Leitura XXI, 2004, p. 25. 
(castelhanas) fosse minimizado ou mesmo omitido. Um bom exemplo é a história dos Sete Povos das Missões, que não é considerada como parte da história do Rio Grande do Sul simplesmente porque os jesuítas estavam a serviço da Coroa espanhola. [KÜHN, 2004, p. 26]

Para Kühn, a compreensão da fronteira sul da colônia portuguesa deve ser feita através da aceitação de que não havia um limite claramente estabelecido, pois a fronteira precisa ser compreendida como em constante movimento durante o período colonial, "com intensa circulação de homens e mercadorias, em um contexto demográfico heterogêneo e numa conjuntura de instabilidade política"12.

Sobre a Colônia do Sacramento, Fábio Kühn apresenta um breve histórico sobre sua fundação em 1680 como reação ao fim da União Ibérica e à consequente expulsão dos portugueses de Buenos Aires, além de seu afastamento do lucrativo comércio com os castelhanos. $\mathrm{O}$ autor ainda afirma que, além dos interesses comerciais, Sacramento foi fundada como um trunfo português, para servir como moeda de troca com os castelhanos quando fosse conveniente, o que acabou por acontecer quando, em troca de Sacramento, os portugueses exigiram a retirada dos jesuítas espanhóis dos Sete Povos das Missões, embora este acordo não tenha sido de fácil execução devido à resistência dos índios e dos jesuítas que ocupavam este território.

$\mathrm{O}$ autor contextualiza todos os movimentos de tomada e

${ }^{12}$ Idem, p. 27. 
retomada da Colônia do Sacramento entre portugueses e espanhóis que foram realizados ao longo do século XVIII, além de todos os acordos diplomáticos assinados entre as duas coroas, embora estes fossem muitas vezes desobedecidos nas colônias. O último tratado firmado foi o de Santo Ildefonso, em 1777. Este tratado "previa a entrega definitiva da Colônia aos espanhóis, sem nenhuma contrapartida"13, o que colocava Portugal em desvantagem em relação a Castela. O valor do continente do Rio Grande era significativo para os portugueses, embora estes só tenham conseguido a posse da região das Sete Missões após a expulsão dos jesuítas (1768).

O historiador Fabrício Prado faz parte de uma geração livre das dores e das ideologias nacionalistas e, portanto, escreve uma obra sobre Sacramento menos parcial, buscando dar os devidos créditos a esta praça que foi fundada às margens do Rio da Prata. Em sua dissertação ${ }^{14}$, que posteriormente virou livro, Fabrício Prado busca reinserir a Colônia do Sacramento na história do Brasil e dar a ela o devido valor que a mesma teve na história do Brasil colônia, no avanço para o extremo sul e nas relações comerciais e diplomáticas entre Portugal e Castela.

Fabrício Prado busca - em muitos momentos - reconstruir uma boa imagem para Sacramento, pois a mesma havia sido denegrida por muitas décadas através da historiografia nacionalista, fazendo com que a mesma fosse inclusive excluída totalmente da nossa história. $\mathrm{O}$ autor busca demonstrar toda a importância comercial e estratégica de seu

\footnotetext{
${ }^{13}$ Idem, p. 38.

${ }^{14}$ PRADO, Op. cit.
} 
posicionamento, bem como sua vida cotidiana e as relações com Buenos Aires, voltando-se para uma matriz historiográfica que aceita as influências castelhanas na constituição do Rio Grande do Sul, e mais ainda na própria Colônia.

Por fim, selecionei 4 livros didáticos para Ensino Fundamental e Médio ${ }^{15}$ disponíveis na biblioteca aos alunos de uma escolar particular em Curitiba.

No livro de Nelson Piletti ( $7^{a}$ série), vemos a expansão ao extremo sul da colônia como consequência da grande quantidade de gado vacum "selvagem" presente na região. Para o autor, "portugueses e paulistas começaram a se estabelecer [no sul], aproveitando o gado disperso que lá ficara após a destruição das Missões"16, ignorando portanto o fato dos Sete Povos das Missões terem sido destruídos depois do Tratado de Madrid, em 1750, e que os portugueses avançaram para o sul a partir da fundação da Colônia do Sacramento, 1680. As fundações de Laguna (1676 ou 1684 - as datas divergem) e de Rio Grande de São Pedro (1737) fizeram parte deste processo expansionista português ignorado por Piletti. O autor até chega a citar a assinatura dos tratados de Utrecht (1715), de Madrid (1750) e de Santo Ildefonso

15 BOULOS JUNIOR, Alfredo. Coleção História, Sociedade e Cidadania. Alfredo Boulos Junior. São Paulo: FTD, 2004, v. 3, $8^{\circ}$ ano; FIGUEIRA, Divalte Garcia. Série Novo Ensino Médio: História, volume único. - São Paulo: Ática, 2007; PILETTI, Nelson. História e vida integrada: livro para análise do professor / Nelson Piletti, Claudino Piletti. - Nova ed. reform. e atual. - São Paulo: Ática, 2005, v. 3, $7^{\text {a }}$ série; RODRIGUE, Joelza Ester, História em documento: imagem e texto / Joelza Ester Rodrigue. - São Paulo: FTD, 2001. - (Coleção História em documento: imagem e texto) v. $2,6^{\mathrm{a}}$ série.

${ }^{16}$ PILETTI, Op. cit., p. 43. 
(1777), mas não contextualiza a assinatura destes tratados em relação às ações que levaram que os mesmos fossem acordados entre as Coroas Portuguesa e Espanhola. $\mathrm{O}$ autor praticamente ignora inclusive a existência dos Sete Povos das Missões e credita o início da povoação do sul ao período posterior ao ano de 1750 , logo, tampouco trata da existência da Colônia do Sacramento e de sua relevância no período em que pertenceu ao Império Português.

Já no livro de Joelza Ester Rodrigue, sequer vemos os tratados assinados entre Portugal e Castela serem apresentados. Portanto, podese concluir que a colonização do sul da colônia também foi omitida em sua obra. Não há uma linha sequer que explique ou justifique a ida ao sul.

Na obra do autor Divalte Garcia Figueira, a fundação da Colônia do Sacramento é descrita como parte do processo expansionista português do século XVII que fundou Paranaguá (1648), Curitiba (1668), Nossa Senhora do Desterro (atual Florianópolis - 1675) e Laguna (1676). O autor contextualiza o fato de que a fundação da Colônia do Sacramento foi vista como uma afronta pelos castelhanos de Buenos Aires, e por isso foi um território constantemente disputado belicamente.

Entre os quatro livros por mim selecionados, o que tem uma abordagem mais completa é o de Alfredo Boulos Junior. Em seu livro, Boulos Junior apresenta a Colônia do Sacramento como uma cidade de fundação portuguesa, fundada para suprir o desejo expansionista do 
monarca português. $\mathrm{O}$ autor aponta que a região compreendida entre Sacramento e Laguna era considerada "terra de ninguém", pois no século XVII não haviam espanhóis nem portugueses nessas terras.

A expansão e colonização mais efetiva do sul acontece a partir de 1730, segundo o autor, e só é empreendida devido à necessidade de gado para abastecer a região das Minas Gerais. Em seguida, o autor explica brevemente os tratados de Utrecht, de Madrid, de Santo Ildefonso e de Badajós (1801), além de contextualizar brevemente os termos de cada tratado no quesito de ganhos e perdas de terras da Coroa Portuguesa. Embora sua explicação seja sucinta como as dos outros dois autores que citaram Sacramento e a expansão ao sul, esta se faz de maneira mais completa e verídica, sem menosprezar Sacramento por ser um território perdido.

Com esta breve revisão historiográfica, nota-se que na historiografia nacionalista do final do século XIX e início do século XX há uma vergonha e um repúdio à história da Colônia do Sacramento enquanto território fundado por portugueses, mas perdido aos castelhanos. Ao compararmos um mapa do Brasil do século XVIII com um dos fins do século XIX, vemos de maneira clara a representativa expansão a oeste e ao sul, com muitos territórios conquistados que ultrapassam o limite do Tratado de Tordesilhas. A Colônia do Sacramento é um dos poucos - senão o único - território que fora perdido, portanto representa uma vergonha, e para tentar superar esta mácula, a historiografia nacionalista prefere denegrir ou simplesmente 
ignorar sua existência e importância na História do Brasil Colonial.

Já nos trabalhos historiográficos mais recentes, como os de Fábio Kühn e de Fabrício Prado, vemos um rompimento com a historiografia nacionalista que tenta apagar Sacramento da nossa história e da nossa memória. Há, por outro lado, um resgate das origens e do valor da Colônia do Sacramento. Apesar desta revisão historiográfica mais recente, vemos nos livros didáticos por mim analisados, que se encontram escritos na última década, uma grande omissão da Colônia do Sacramento, quando não um silêncio total em relação à sua existência.

\section{Os usos de Simão Pereira de Sá e da sua Historia Topografica}

A dissertação de mestrado de Viviane Sueli Marques, intitulada Edição semidiplomática de História topográfica e bélica da Nova Colonia do Sacramento do Rio da Prata, códice 677, da Biblioteca Nacional de Lisboa ${ }^{17}$, é uma análise filológica e linguística que faz uso da obra de Simão Pereira de Sá - a crônica Historia Topografica e Belica da Nova Colonia do Sacramento do Rio da Prata. Embora a autora foque nas questões linguísticas, no primeiro capítulo de sua dissertação ela busca contextualizar historicamente o autor e sua obra, apresentando inclusive uma breve história da própria Colônia do

\footnotetext{
17 MARQUES, Viviane Sueli. Edição semidiplomática de História topográfica e bélica da Nova Colônia do Sacramento do Rio da Prata, códice 677, da Biblioteca Nacional de Lisboa. (Dissertação de Mestrado) - USP, São Paulo, 2008.
} 
Sacramento.

Neste intuito de apresentar a história da Colônia do Sacramento e ressaltar a importância da obra de Pereira de Sá, Viviane Marques comete o erro de acreditar que as intenções do autor são desinteressadas. Embora não use Pereira de Sá como detentor da verdade, para contar uma história, a autora acredita em suas palavras e busca defendê-lo e legitimar a sua escrita através das palavras de José Honório Rodrigues, onde afirma que a obra tem um "estilo retórico, seu conteúdo é episódico e eventual, sem nenhum interesse social e econômico"18.

Na obra de Fabrício Prado anteriormente utilizada aqui vemos usos mais diretos de Simão Pereira de Sá e de sua crônica como detentoras da verdade. Embora o autor tenha uma visão e postura mais críticas e independentes do que a historiografia nacionalista, quando se trata do uso de Simão Pereira de Sá, Prado age de maneira no mínimo inocente. O autor cita a Historia Topografica e Belica algumas vezes em seu livro, de maneira a contextualizar o cotidiano da Colônia do Sacramento, mas isso sem levar em consideração quem foi Simão Pereira de Sá e quais foram as motivações de sua escrita. Embora na introdução o autor faça uso de maneira crítica e aponte alguns equívocos de Moysés Vellinho e Capistrano de Abreu ao denegrir a Colônia sem considerar diversos fatores importantes, no uso de Simão Pereira de Sá Fabrício Prado cai para o outro extremo: o uso da crônica

${ }^{18}$ RODRIGUES, José Honório apud MARQUES, Op. cit., p. 15. 
para "defender" Sacramento, para relocar Sacramento na nossa história e historiografia, mas sem um olhar crítico.

Alguns dos trechos de Simão Pereira de Sá utilizados por Prado podem ser considerados inocentes, ou pelo menos sem a grande exaltação aos portugueses e à Colônia do Sacramento como vemos em outros momentos, como, por exemplo, ao falar dos preparativos para tentar um contra-ataque aos castelhanos em 1737, onde Prado afirma que "Silva Paes desembarcou na barra do Rio Grande de São Pedro. Cristóvão Pereira e Domingo Fernandes, que haviam avançado com os preparativos de Laguna, o esperavam"19. Não há um uso exacerbado da retórica e de exageros linguísticos por parte de Simão Pereira de Sá, portanto não é um trecho perigoso para se basear.

Em outros momentos, entretanto, vemos toda a veia retórica de Simão Pereira de Sá em ação, e mesmo assim Fabrício Prado utiliza-se dos escritos desse de maneira acrítica. Ao referir-se ao início do governo de Antônio Pedro de Vasconcelos sob a Colônia do Sacramento, Prado faz a seguinte afirmação e uso de Pereira de Sá:

para a garantia da cidade, e buscando aumentar a segurança das adjacências das muralhas, consolidouse, a partir do ano de 1722, sob a administração do hábil governador Antônio Pedro de Vasconcelos, obras de estruturação e fortificação da Praça. Buscou-se garantir a permanência dos povoadores e a manutenção do comércio [...] "....comessou a augmentar illustremente a Povoação, cingindo a Fortaleza de muralhas mais robustas. Cuidou o

${ }^{19}$ PRADO, Op. cit., p. 54. 
mesmo da fortificação e bem publico, civilizando os moradores, q. contra a necessaria regularidade seguião na construção dos edifícios as propensões do interesse, os affectos da vontade"20. [PRADO, 2002, p. 96]

Aqui Prado parece ignorar o trecho anterior do escrito de Pereira de Sá. Nos parágrafos anteriores, Pereira de Sá está a se referir a uma das batalhas travadas entre os portugueses e os castelhanos nas proximidades da Colônia. No contexto do texto, notamos que Pereira de Sá queria neste momento, mais do que elogiar a Colônia do Sacramento, elogiar o novo governador que nela fora estabelecido, buscando demonstrar que conquanto o último governador tivesse sido bom, esse seria ainda melhor.

Num outro trecho, Fabrício Prado, além de fazer uso indiscriminado da crônica de Simão Pereira de Sá, afirma que o relato rico "da realidade urbano-demográfica da praça" foi feito in loco por Simão Pereira de Sá, embora não apresente documentação para provar sua afirmação. Na realização deste trabalho procurei indícios da presença de Simão Pereira de Sá em Sacramento para a escrita de seu terceiro relato, mas nada foi encontrado. Em relação à própria crônica, Fabrício Prado comenta o trecho por ele utilizado nos seguintes termos:

pode-se inferir, a partir das impressões registradas por Simão Pereira de Sá, que a concentração demográfica que o núcleo urbano parece ter atingido foi alta, determinando seu crescimento nos arrabaldes extra-muros. Tal fato foi reflexo de um

${ }^{20}$ SÁ, Simão Pereira deapud PRADO, Op. cit.., p. 96. 
progressivo crescimento da importância da cidade em diversas dimensões para as comunidades da região. Sacramento possuía uma vida interna agitada, era um pólo de sociabilidade, comércio, prostituição, lugar de obtenção de bebida e tabaco... Colônia, ao longo da primeira metade dos 1700 tornou-se, progressivamente, um centro regional, integrado num complexo maior, do qual constituía apenas uma das partes: era a principal cidade-porto da Banda Oriental [PRADO, 2002, p. 104].

Fabrício Prado, além de fazer uso indiscriminado e acrítico da crônica de Simão Pereira de Sá, comenta o trecho por ele citado atribuindo uma verdade inegável e inquestionável às palavras de Pereira de Sá. Prado parece ignorar que a crônica fora feita sob encomenda de Gomes Freire de Andrade, e tinha algumas finalidades em si, como provavelmente convencer a Coroa portuguesa do valor de Sacramento.

Da historiadora Martha Daisson Hameister selecionei dois trabalhos que fazem uso da crônica de Simão Pereira de Sá de maneira acrítica: "O continente do Rio Grande de São Pedro: os homens, suas redes de relação e suas mercadorias semoventes (c. 1727 - c. 1763)" e "No princípio era o caos: a formação de um povoado na fronteira americana dos Impérios Ibéricos através do estudo das relações de compadrio",21.

Os usos que Hameister faz de Simão Pereira de Sá são mais

${ }^{21}$ HAMEISTER, Martha Daisson. O continente do Rio Grande de São Pedro: os homens, suas redes de relações e suas mercadorias semoventes (c. 1727 - c. 1763); HAMEISTER, Martha Daisson. No princípio era o caos: a formação de um povoado na fronteira americana dos Impérios Ibéricos através do estudo das relações de compadrio. Revista de História Regional, v. 15, 2010. 
pontuais do que os vistos em Fabrício Prado. Em sua dissertação de mestrado, Hameister vale-se da Historia Topografica e Belica para apresentar Cristóvão Pereira de Abreu. Ali a autora usa diversos dos relatos e elogios vindos por parte de Pereira de Sá na descrição de Pereira de Abreu, sem - a princípio - levar em conta os interesses por trás de seu tom elogioso. A autora afirma que em seu texto "não se questionam aqui os atos de bravura e as atitudes singulares de Cristóvão Pereira de Abreu, pois assim procedendo, estariam sendo jogados fora os relatos e parte do juízo que dele faziam seus coevos" 22 e que tais relatos foram inspirados em parte na obra de Simão Pereira de Sá, onde o autor, "ao contar as façanhas de Cristóvão Pereira de Abreu, empresta-lhe modos quase que sobre-humanos" 23 , e que, por sua vez, nem mesmo os modos quase sobre-humanos, frutos da retórica exacerbada de Simão Pereira de Sá, foram indícios para a autora de que era necessário tomar cuidado com as palavras envolventes e cativantes de Pereira de Sá. A autora usa inclusive termos recorrentes na crônica de Pereira de Sá ao se referir a outros homens, os ditos "heróis da Sacramento sitiada" 24 .

Embora pareça ingênua ao fazer tal uso de Simão Pereira de Sá, Hameister afirma posteriormente que é possível perceber o trabalho retórico de Simão Pereira de Sá, "que reforçando-se aspectos singulares e 'esquecendo-se' de outros, se obtém a legitimação para a própria

\footnotetext{
${ }^{22}$ HAMEISTER. O continente do Rio Grande de São Pedro, p. 112.

${ }^{23}$ Idem, ibidem.

${ }^{24}$ Idem, ibidem.
} 
hierarquização da sociedade em surgimento" ${ }^{25}$. Por mais que a autora não se proponha a analisar as qualidades retóricas de Pereira de Sá, ela percebe as armadilhas habilmente traçadas por ele.

Já em seu artigo "No princípio era o caos: a formação de um povoado na fronteira americana", o uso de Simão Pereira de Sá se limita a uma breve contextualização da Colônia do Sacramento na década de 1720, onde a autora aponta a riqueza da narrativa feita por Pereira de Sá nesta fase de colonização de Sacramento, o que não é necessariamente um exagero, pois a crônica de Pereira de Sá ganha outros ares em seu Livro III, onde o relato do autor é de fato rico e completo, embora devase olhar com cuidado os elogios e exaltações feitas por Pereira de Sá ao longo de toda sua crônica.

Outro autor que tem trabalhos voltados para a Colônia do Sacramento é Paulo César Possamai. A produção acadêmica de Possamai é quase inteiramente voltada para a Colônia do Sacramento, tendo diversos artigos sobre a mesma, além de sua tese de doutorado intitulada $O$ Cotidiano da Guerra: A vida na Colônia do Sacramento (1715-1735), à qual não tive acesso.

Para analisar os usos de Simão Pereira de Sá em Possamai, selecionei dois artigos deste autor ${ }^{26}$ dos quais falarei brevemente a seguir. Em "A Colônia do Sacramento: Uma praça de guerra do Império

\footnotetext{
${ }^{25}$ Idem, p. 113.

${ }^{26}$ POSSAMAI, Paulo César. A Colônia do Sacramento: Uma praça de guerra do Império Colonial Português. História em Revista, Pelotas, v. 13, p. 9-28, 2007; POSSAMAI, Paulo César. De núcleo de povoamento a praça de guerra: a Colônia do Sacramento de 1735-1777. Topoi, v. 11, n. 21, p. 23-36, jul./dez. 2010.
} 
Colonial Português", Possamai se vale da crônica de Simão Pereira de Sá num único momento, enquanto ele traça paralelos entre as forças de defesa de Sacramento com outras empresas lusas, principalmente aquelas empreendidas no Oriente, como na Índia e no Marrocos. Segundo o autor,

também as atuações militares desastrosas ou as heróicas defesas dos muros de Sacramento encontram muitos paralelos com a história dos portugueses no Oriente. [...] O mesmo se pode dizer da atuação dos portugueses nas praças de guerra do litoral marroquino, em cujas muralhas muitas vezes as mulheres combateram ombro a ombro com os homens, como aconteceu na Colônia do Sacramento por ocasião do sítio espanhol. Em 1736, quando os inimigos tentaram tomar de assalto o povoado, segundo o cronista Simão Pereira de Sá, as mulheres "largaram as almofadas, e pegaram nas lanças, arrimando-se às muralhas com espíritos tão estranhos ao sexo, que pareceram acostumadas àquele robusto exercício"27. [POSSAMAI, 2007, p. 23].

Embora possamos acreditar que de fato as mulheres pegaram em armas para defender a Praça e a si mesmas, é de se questionar a forma com que Pereira de Sá retrata tal evento. Acreditar que um cronista formado em Coimbra - portanto com uma educação bem tradicionalista - visse com um olhar elogioso mulheres às armas pelo simples fato destas estarem a defender sua Praça tão valorosamente quantos os homens é no mínimo ingenuidade.

${ }^{27}$ SÁ, Simão Pereira apud POSSAMAI,“A Colônia do Sacramento...”, p. 23. 
Já no artigo "De núcleo urbano a praça de guerra: a Colônia do Sacramento de 1735-1777", Possamai utiliza de maneira ainda mais indiscriminada e em diferentes momentos a crônica de Simão Pereira de Sá. O autor se vale da crônica para narrar episódios de desavenças entre soldados recém-chegados da Bahia em auxílio à Colônia e os moradores locais, as indisposições entre os comerciantes alocados aos líderes militares e soldados sob suas ordens que não os obedeciam, além da importante contribuição dos comerciantes à guerra. Possamai argumenta, baseando-se em Pereira de Sá, que aos comerciantes cabia a função "de fornecer empréstimos que possibilitassem ao governador Vasconcelos realizar o pagamento das tropas" ${ }^{\prime 28}$, pois assim se evitaria a insubordinação dos soldados a seus superiores por insatisfação devido à falta de pagamento de seus soldos.

Os últimos usos da crônica de Simão Pereira de Sá se dão no sentido de relatar os dias de fome em que a Colônia do Sacramento se encontrava devido ao forte cerco imposto pelos castelhanos. Enquanto Pereira de Sá afirma que nem mesmo cachorros, gatos e ratos fugiam de servir de alimento aos moradores da Colônia, a linha de interpretação pode seguir em duas vias diferentes: na primeira, Pereira de Sá poderia querer demonstrar quão desesperadora estava a situação da Praça, a tal ponto de levar seus moradores a se rebaixar a tal ponto; na segunda poderia ser percebida uma maneira chocante e forte de exigir maiores esforços da Coroa no envio de tropas e mantimentos para que se

\footnotetext{
${ }^{28}$ POSSAMAI, Paulo César. "De núcleo de povoamento a praça de guerra...”, p. 27.
} 
continuasse a defesa da Praça. Baseada no contexto em que Possamai insere tal texto, creio que ele se valeu da primeira interpretação, a mais fácil. Pereira de Sá apenas relatava um fato. Baseada em minha leitura e interpretação da fonte, acredito que Pereira de Sá pendia mais à segunda interpretação, na qual mostrava o valor dos homens e mulheres da Colônia mesmo em meios insalubres de vida, que continuavam lutando, e portanto mereciam ser ajudados a todo custo.

A partir da leitura de textos que utilizaram Simão Pereira de Sá como fonte, é possível notar o uso ingênuo e acrítico da sua crônica. Por mais elaborada que seja a retórica do autor, cabe ao historiador tentar compreendê-la e se livrar das armadilhas preparadas ao longo do caminho.

\section{Referências}

ABREU, Capistrano de. Capítulos da História Colonial: 1500-1800. Brasília: Conselho Editoral do Senado Federal, 1998. Disponível em: http://www.dominiopublico.gov.br/pesquisa/DetalheObraForm.do?selec t_action=\&co_obra $=2074$

ALMEIDA, Carina Santos de. O debate historiográfico entre Moysés Vellinho e Manoelito de Ornellas. Spartacus - Revista Eletrônica dos Discentes de História, 2007.

BOUlOS JUNIOR, Alfredo. Coleção História, Sociedade e Cidadania. São Paulo: FTD, 2004, v. 3, $8^{\circ}$ ano.

FIGUEIRA, Divalte Garcia. Série Novo Ensino Médio: História, volume único. São Paulo: Ática, 2007. 
GUTFREIND, Ieda. A Historiografia Rio-Grandense. $2^{\mathrm{a}}$ ed. Porto Alegre: Ed. Universidade/UFRGS, 1998.

HAMEISTER, Martha Daisson. O continente do Rio Grande de São Pedro: os homens, suas redes de relação e suas mercadorias semoventes (c. 1727 - c. 1763). (Dissertação de Mestrado). UFRJ, Rio de Janeiro, 2002.

Disponível

em:

http://www.dominiopublico.gov.br/pesquisa/DetalheObraForm.do?selec t_action=\&co_obra $=18909$

. No princípio era o caos: a formação de um povoado na fronteira americana dos Impérios Ibéricos através do estudo das relações de compadrio. Revista de História Regional, v. 15, 2010. Disponível

em: http://www.revistas2.uepg.br/index.php/rhr/article/viewFile/2374/1869

KÜHN, Fábio. Breve História do Rio Grande do Sul. $2^{\mathrm{a}}$ edição. Porto Alegre: Leitura XXI, 2004.

MARQUES, Viviane Sueli. Edição semidiplomática de História topográfica e bélica da Nova Colônia do Sacramento do Rio da Prata, códice 677, da Biblioteca Nacional de Lisboa. (Dissertação de Mestrado). USP, São Paulo, 2008. Disponível em: http://www.teses.usp.br/teses/disponiveis/8/8142/tde-25112009110609/pt-br.php

PILETTI, Nelson. História e vida integrada: livro para análise do professor. Nelson Piletti, Claudino Piletti. Nova ed. reform. e atual. São Paulo: Ática, 2005, v. 3, $7^{\mathrm{a}}$ série.

POSSAMAI, Paulo C. A vida quotidiana na Colônia do Sacramento. Lisboa: Livros do Brasil, 2006.

; A Colônia do Sacramento: Uma praça de guerra do Império Colonial Português. História em Revista, Pelotas, v. 13, p. 0928, 2007. Disponível em: http://ich.ufpel.edu.br/ndh/downloads/historia_em_revista_paulo_possa mai.pdf 
- De núcleo de povoamento a praça de guerra: a Colônia do Sacramento de 1735-1777. Topoi, v. 11, n. 21, p. 23-36, jul./dez. 2010. Disponível em: http://www.revistatopoi.org/numeros_anteriores/topoi21/Topoi21_02Ar tigo2.pdf

PRADO, Fabrício. Colônia do Sacramento: O Extremo Sul da América Portuguesa. Porto Alegre: Prefeitura Municipal de Porto Alegre, 2002.

RODRIGUE, Joelza Ester. História em documento: imagem e texto. São Paulo: FTD, 2001. (Coleção História em documento: imagem e texto) v. $2,6^{\mathrm{a}}$ série.

SÁ, Simão Pereira de. Historia Topografica e Belica da Nova Colonia do Sacramento do Rio da Prata, Escrita por Ordem do Governador e Capitão Geral do Rio de Janeiro em 1737 e 1777. Porto Alegre: Arcano 17, 1993.

SPALDING, Walter. Gênese do Brasil-Sul. Porto Alegre: Livraria Sulina Editora, 1953.

VELLINHO, Moysés. Fronteira. Porto Alegre: Editora Globo, 1975.

Artigo recebido em 27/11/2015, aceito em 23/01/2016 